\title{
Application of 2015 American Gastroenterological Association Guidelines On a Retrospective Cohort of Patients with Asymptomatic Pancreatic Cysts: Can We Truly Forego Endoscopic Ultrasound?
}

\author{
Anam Omer, Ali Raza', Ross A. Miller², Dina R. Mody², Kumar Krishnan ${ }^{1}$
}

Department of Medicine, Houston Methodist Hospital, Weill Cornell Medicine, ${ }^{1}$ Division of Gastroenterology, Houston Methodist Hospital, Weill Cornell Medicine, ${ }^{2}$ Department of Pathology and Genomic Medicine, Houston Methodist Hospital, Weill Cornell Medicine, Houston, TX 77030, USA Objective: Asymptomatic pancreatic cysts are frequently diagnosed on cross-sectional imaging. Recently, the American Gastroenterological Association (AGA) has put forth guidelines regarding management of these cysts. To date, there is no strong data to indicate whether these guidelines will accurately identify malignancy and mitigate unnecessary endoscopic ultrasound (EUS) procedures. The aim of this investigation was to apply the 2015 AGA guidelines to a retrospective cohort of asymptomatic pancreatic cysts in a large regional referral center. Materials and Methods: This is a retrospective cohort study of patients with asymptomatic pancreatic cysts who underwent EUS with fine-needle aspiration (FNA) over a 3-year period. We applied current AGA guidelines to determine how many EUS procedures would be avoided, and further assessed whether the guidelines adequately identified cases of malignancy. Results: Forty-five patients were identified who underwent EUS FNA for an asymptomatic pancreatic cyst from 2011 to 2014. The mean age was 65 years, and the mean size cyst size was $2.8 \mathrm{~cm}$. According to the 2015 AGA guidelines, EUS was indicated in 13 of the 45 patients and surveillance imaging in the remaining 32 patients. 3 of these 32 patients had atypical cytology on EUS FNA, and final histology showed adenocarcinoma in 2 patients and IMPN with high-grade dysplasia in 1 patient. Conclusion: Applying AGA guidelines in this study cohort would have prevented 32 out of 45 (71\%) EUS procedures; however, 3 of these 32 patients had early occult malignancy. This data suggest that additional strategies are needed to identify those patients at high risk.

KEYWORDs: American gastroenterology association, endoscopic ultrasound-guided fine needle aspiration, guideline, pancreatic cyst, pancreatic neoplasm

\section{INTRODUCTION}

$P$ ancreatic cysts are a heterogeneous group of lesions that are increasingly found incidentally due to advances and increased utilization of cross-sectional imaging. ${ }^{[1]}$ The reported incidence varies in the medical literature; however, it is often reported as $0.2 \%$ on ultrasonography, $2.5 \%-3 \%$ on computerized tomography (CT), and $14 \%-20 \%$ on magnetic resonance imaging (MRI). ${ }^{[1-5]}$ The appropriate management of these incidental pancreatic cysts remains controversial. Identification of these incidental pancreatic cysts

\begin{tabular}{|l|l|}
\hline \multicolumn{2}{|c|}{ Access this article online } \\
\hline Quick Response Code: & \\
\hline & \\
\hline
\end{tabular}

often leads to a high degree of anxiety in patients. Pseudocysts and serous cysts fall into the benign category while mucinous cysts may be precursor lesions or harbor adenocarcinoma. ${ }^{[6-8]}$ To date, the only treatment option that reliably prevents cancer in patients with premalignant lesions is surgical resection. ${ }^{[7,9]}$ As a result,

Address for correspondence: Dr. Kumar Krishnan, Houston Methodist Hospital, Weill Cornell Medicine, Houston Campus, 6550 Fannin Street, Smith 1201, Houston, TX 77030, USA. E-mail: kkrish02@gmail.com

This is an open access article distributed under the terms of the Creative Commons Attribution-NonCommercial-ShareAlike 3.0 License, which allows others to remix, tweak, and build upon the work non-commercially, as long as the author is credited and the new creations are licensed under the identical terms.

For reprints contact: reprints@medknow.com

How to cite this article: Omer A, Raza A, Miller RA, Mody DR, Krishnan K. Application of 2015 American Gastroenterological Association Guidelines On a Retrospective Cohort of Patients with Asymptomatic Pancreatic Cysts: Can We Truly Forego Endoscopic Ultrasound? J Dig Endosc 2018;9:1-5. 
guidelines have been proposed to risk stratify patients with these asymptomatic cysts.

The first of these proposed guidelines was the "Sendai guidelines," published in 2006. ${ }^{[10]}$ These guidelines gave recommendations on management of intraductal papillary mucinous neoplasms (IPMNs) and mucinous cystic neoplasms and proposed imaging surveillance for cysts $<3 \mathrm{~cm}$ in size and surgical resection for cysts $\geq 3 \mathrm{~cm}$ or cysts with any worrisome clinical/imaging findings including pancreatic duct (PD) dilation, presence of a mural nodule, or malignant cytopathology findings. Low specificity, reported at $21.5 \%{ }^{[11]}$ in one follow-up study, led to a revision of these guidelines in 2012 by the International Association of Pancreatolgy (Fukuoka guidelines) ${ }^{[12]}$ These guidelines utilized endoscopic ultrasound (EUS) fine-needle aspiration (FNA) as a diagnostic tool. According to these guidelines, the presence of even one worrisome feature, i.e., cyst size $\geq 3 \mathrm{~cm}$, thickened or enhanced cyst walls, main PD size between 5 and $9 \mathrm{~cm}$, nonenhancing mural nodule or an abrupt change in the caliber of PD with distal pancreatic atrophy warranted further evaluation with an EUS to help visualize the detailed morphology of the pancreatic cyst as well as to obtain cyst fluid via FNA for analysis to differentiate mucinous from non-mucinous cysts. Follow-up studies reported improved specificity, $73 \%$ but low sensitivity, $55.6 \%$. ${ }^{[1]}$

The American Gastroenterology Association published a position statement regarding the management of incidental pancreatic cysts in 2015. ${ }^{[13]}$ These guidelines specifically targeted patients with asymptomatic pancreatic cysts. The most controversial aspect of these guidelines was the increased threshold for performing EUS FNA. According to these guidelines, EUS with FNA was suggested for patients with two or more high-risk features defined as cysts size $>3 \mathrm{~cm}$, PD dilatation, solid component, or the presence of a mural nodule. In addition, they recommend discontinuation of surveillance after 5 years in the absence of significant changes.

The aim of this study was to determine the outcome of patients with incidental pancreatic cysts who underwent EUS FNA who would have met the criteria for surveillance only based on the 2015 American Gastroenterological Association (AGA) guidelines. In addition, we looked at the accuracy of AGA guidelines in identifying malignancy in our patient cohort.

\section{Materials and Methods}

\section{Study population}

This was a single-center retrospective cohort of clinical and radiographic data of patients who underwent the
EUS FNA for asymptomatic pancreatic cysts between 2011 and 2014.

\section{Inclusion and exclusion criteria}

Patients diagnosed with incidental pancreatic cysts on cross-sectional imaging who underwent EUS were included in the study. Patients with a history of pancreatitis suspected to have pseudocysts, a pancreatic mass on imaging, known pancreatobiliary malignancy, or patients with a history of pancreatic surgery were excluded from the study.

\section{Data collection and analysis}

Study approval was obtained from Houston Methodist Hospital Institutional Review Board. A cytopathology database search was performed to identify patients who underwent EUS FNA between 2011 and 2014 by an experienced interventional gastroenterologist at Houston Methodist Hospital. 284 patients with pancreatic cysts who underwent EUS examinations were identified; 45 of the patients met the criteria set for this study. For each patient, demographics including age, gender, clinical findings, cysts features on cross-sectional imaging (CT and MRI), EUS findings (including cyst size, location, PD dilation, mural node, or solid component), FNA results, and cyst fluid amylase and carcinoembryonic antigen (CEA) levels were reviewed. Surgical pathology data were also examined in those patients who underwent subsequent resection procedures.

We then retrospectively applied the AGA guidelines on the management of asymptomatic pancreatic cysts to our final patient cohort; and divided the 45 patients into two groups (surveillance or EUS with FNA per 2015 AGA recommendations).

\section{Results}

\section{Patient demographics and cyst characteristics}

A total of 45 patients met our criteria for the study that underwent EUS FNA for pancreatic cysts between 2011 and 2014 [Table 1]. Patients ranged in age from 22 to 86 years with a mean age of 65 years, and $56 \%$ of the patients were female. The cysts were identified by cross-sectional imaging studies on all included patients.

Cyst size ranged between 0.5 and $8 \mathrm{~cm}, 13$ patients (28.9\%) had a cyst sizes $>3 \mathrm{~cm}$. PD dilation was present in 10 cases $(22 \%)$, and a solid component or mural nodule was noted in 5 cases (11\%). FNA was performed, and cytological evaluation and cyst fluid analysis for CEA and amylase was performed on all samples.

Application of American Gastroenterological Association guidelines to study population

Applying the 2015 AGA guidelines, our study cohort was divided into two groups; one with 13 patients 
where EUS FNA was indicated and the second group with 32 patients where surveillance was indicated. In the first group (where EUS FNA was indicated per the 2015 AGA guidelines), 9 of 13 patients (69\%) had benign findings on cytology, and one patient $(8 \%)$ had malignant cells detected on cytology. The remaining specimens were unsatisfactory for cytopathologic diagnosis due to scant or absent cellularity. The mean amylase level in patients with a benign cytology was elevated to 59980, and the mean CEA level was 154.4. However, the patient with a malignant cytology had a mean amylase level of $<20$ and a CEA level elevated to 3270.4 [Table 2].

The second group, (where surveillance was indicated by the 2015 AGA guidelines), consisted of 21 of 32 patients $(65.6 \%)$ with benign cytologic findings; 17 of these 21 cases had one or more high-risk features on EUS evaluation (cysts size $>3 \mathrm{~cm}$, PD dilation, a solid component, or presence of a mural nodule) [Figure 1]. The mean amylase and CEA levels were 4559 and 78.3, respectively. Eight specimens were inadequate for cytopathologic diagnosis, and three patients had atypical cells noted on cytology. In these three patients, the mean amylase level was 224, and the mean CEA level was 14.8. [Table 3] summarizes the cyst characteristics observed on high-resolution MRI and EUS. All three of these cases had surgical resections. The final pathologic diagnosis was adenocarcinoma in two patients and IPMN with high-grade dysplasia in one patient [Table 4]. Figures 2 and 3 show the cytopathologic and histologic characteristics of specimens from one patient.

\section{Discussion}

Thirty-two of the 45 patients in our cohort had an EUS FNA performed outside of the 2015 AGA recommendations. Among these patients, 3/32 (9.4\%) were noted to have advanced histology or early

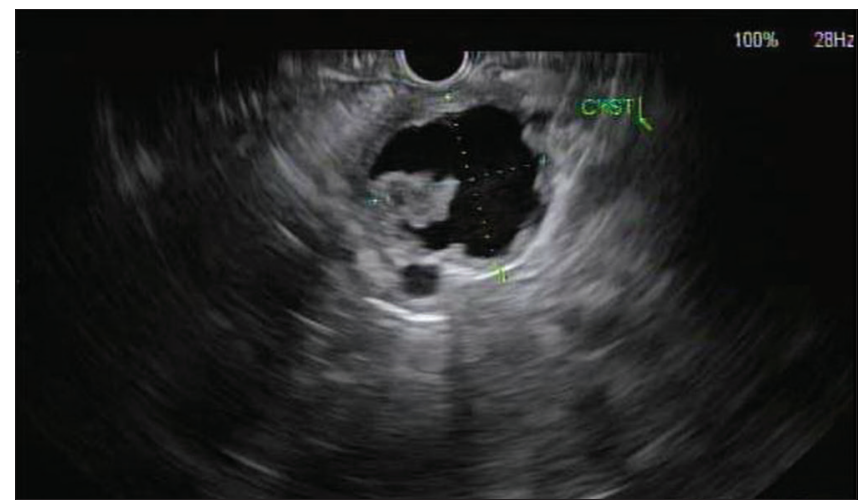

Figure 1: A hypoechoic lesion is noted in the body of the pancreas on endoscopic ultrasound. Within the lesion is a mural nodule. Fine-needle aspiration revealed adenocarcinoma carcinoma. This data suggest that applying the 2015 AGA guidelines would have only provided surveillance in patients who had harbored early malignancy. The current AGA guidelines on the management of pancreatic cysts are the most recent guidelines to risk stratify patients. Unlike previous guidelines, these

\begin{tabular}{|c|c|}
\hline \multicolumn{2}{|c|}{$\begin{array}{l}\text { Table 1: Clinical and demographic data of } \\
\text { patients }(n=45)\end{array}$} \\
\hline \multicolumn{2}{|l|}{ Age (years) } \\
\hline Mean & 65 \\
\hline Range & $22-86$ \\
\hline $\mathrm{SD}$ & 17.4 \\
\hline \multicolumn{2}{|l|}{ Gender (\%) } \\
\hline Male & 44 \\
\hline Female & 56 \\
\hline \multicolumn{2}{|l|}{ Size range $(\mathrm{cm})$} \\
\hline Mean & 2.8 \\
\hline Range & $0.5-8$ \\
\hline SD & 1.5 \\
\hline Cyst size $>3 \mathrm{~cm}(\%),(n=13)$ & 28.9 \\
\hline PD dilatation $(\%),(n=10)$ & 22 \\
\hline Solid component/mural nodule, $(n=5)$ & 11 \\
\hline
\end{tabular}

$\mathrm{PD}=$ Pancreatic duct, $\mathrm{SD}=$ Standard deviation

Table 2: Endoscopic ultrasound performed consistent with American Gastroenterological Association Guidelines

\begin{tabular}{lcccc}
\hline Cytology $(\boldsymbol{n})$ & $\begin{array}{c}\text { Mean } \\
\text { amylase } \\
(\text { IU/L) }\end{array}$ & $\begin{array}{c}\text { Mean } \\
\text { CEA level } \\
(\mathbf{n g} / \mathbf{m l})\end{array}$ & $\begin{array}{c}\text { Repeat } \\
\text { EUS }\end{array}$ & $\begin{array}{c}\text { Malignancy } \\
\text { on repeat } \\
\text { EUS }\end{array}$ \\
\hline Benign (9) & 59,980 & 154.4 & 1 & 0 \\
& SD: 1068.3 & SD: 45.2 & & \\
Malignant (1) & $<30$ & 3270.4 & N/A & \\
& SD: 40.4 & SD: 1058 & & \\
Unsatisfactory for & 300 & 31.6 & 1 & 0 \\
evaluation (3) & SD: 93.1 & 13.3 & & \\
Total patients (13) & & & &
\end{tabular}

$\mathrm{CEA}=$ Carcinoembryonic antigen, EUS=Endoscopic ultrasound, $\mathrm{N} / \mathrm{A}=$ Not available, $\mathrm{SD}=$ Standard deviation

\begin{tabular}{|c|c|c|c|c|}
\hline & & \multirow{2}{*}{$\begin{array}{c}\text { Mean } \\
\text { amylase } \\
\text { level }(\mathrm{IU} / \mathrm{L})\end{array}$} & \multirow{2}{*}{$\begin{array}{c}\text { Mean } \\
\text { CEA level } \\
(\mathrm{ng} / \mathrm{ml})\end{array}$} \\
\hline & \multicolumn{2}{|c|}{$\begin{array}{l}\text { Table 3: Endoscopic ultrasound } \\
\text { American Gastroenterological A } \\
\text { Cytology }(n) \quad \frac{\text { High risk on EUS }}{\text { Yes }}\end{array}$} & & \\
\hline \multirow[t]{2}{*}{ Benign (21) } & 4 & 17 & 4559 & 78.3 \\
\hline & & & SD: 251.3 & SD: 24.3 \\
\hline \multirow[t]{2}{*}{ Atypical (3) } & 3 & 0 & 224 & 14.8 \\
\hline & & & SD: 124.1 & SD: 21.2 \\
\hline \multirow{2}{*}{$\begin{array}{l}\text { Unsatisfactory for } \\
\text { evaluation (8) }\end{array}$} & 0 & 8 & 37700 & 583 \\
\hline & & & SD: 2340 & SD: 143.4 \\
\hline Total patients (32) & & & & \\
\hline
\end{tabular}




\begin{tabular}{|c|c|c|c|c|c|c|c|c|}
\hline & \multicolumn{7}{|c|}{ Table 4: Features of malignant cases } & \multirow{3}{*}{ Surgery outcome } \\
\hline \multirow[t]{2}{*}{ Patient } & \multicolumn{3}{|c|}{ MRI } & \multicolumn{4}{|c|}{ EUS } & \\
\hline & Size (cm) & PD dilation & Mural nodule & Size $(\mathrm{cm})$ & PD dilation & Mural nodule & Cytology & \\
\hline ase 1 & $3.4 \times 2.2 \times 2.7$ & No & No & $3.2 \times 2.7$ & No & Yes & Atypia & Adeno-CA \\
\hline Case 2 & $1.8 \times 1.2 \times 1.0$ & No & No & $1.4 \times 0.9$ & No & Yes & Atypia & Adeno-CA \\
\hline Case 3 & $2.2 \times 1.3 \times 1.1$ & Yes & No & $2.3 \times 2.2$ & Yes & Yes & Atypia & High-grade IPMN \\
\hline
\end{tabular}

IPMN=Intraductal papillary mucinous neoplasm, $\mathrm{PD}=$ Pancreatic duct, EUS=Endoscopic ultrasound, MRI=Magnetic resonance imaging, $\mathrm{CA}=$ Carcinoma

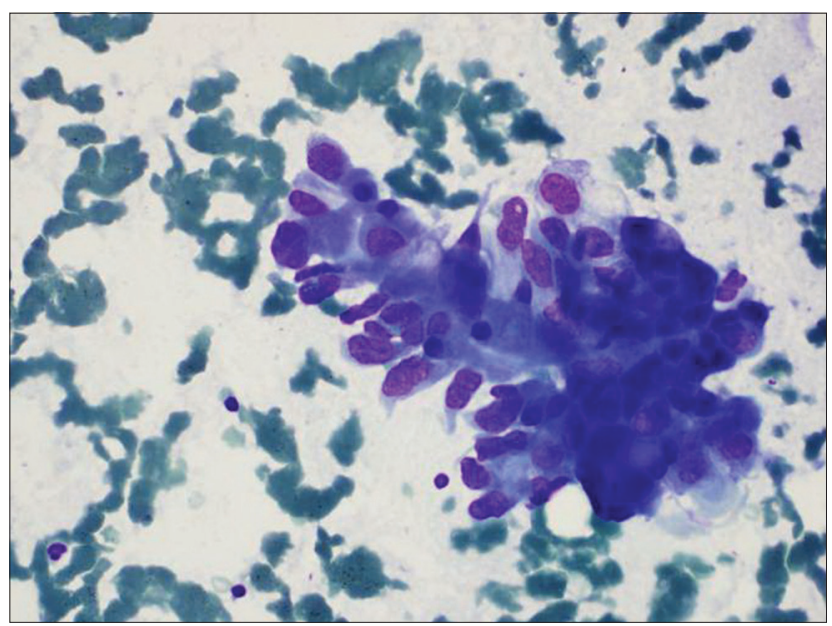

Figure 2: Cytology of sample obtained during endoscopic ultrasound. Diff-Quik (Romanowsky) stain showing a cluster of cells with vacuolated cytoplasm, increased nuclear to cytoplasmic ratio, nuclear pleomorphism, hyperchromasia, and nuclear membrane irregularity

guidelines place a higher threshold for the use of EUS and further suggest discontinuing surveillance altogether in patients who demonstrate stable lesions after 5 years. In our study, $9.4 \%$ of the cases in the surveillance group harbored malignancy.

Cystic neoplasms of the pancreas represent a challenging condition to manage. While they have an overall low risk of malignancy, the risk of a precancerous lesion in the pancreas can result in substantial anxiety for many patients. Guidelines have been developed in attempts to minimize unnecessary surgery while detecting patients with lesions needing further intervention.

Our data are in line with two recent studies which evaluate the AGA guidelines. In one study, 4/33 (12\%) patients were found to have high-grade dysplasia or malignancy, who would have otherwise been missed using the AGA guidelines. ${ }^{[14]}$ Another retrospective surgical cohort also revealed that the AGA guidelines would have missed 30/239 (12.5\%) of patients with early neoplasia. ${ }^{[14,15]}$ The study provides supporting data and emphasizes the utility of EUS as a minimally invasive diagnostic tool in the management of patients with incidental pancreatic cysts.

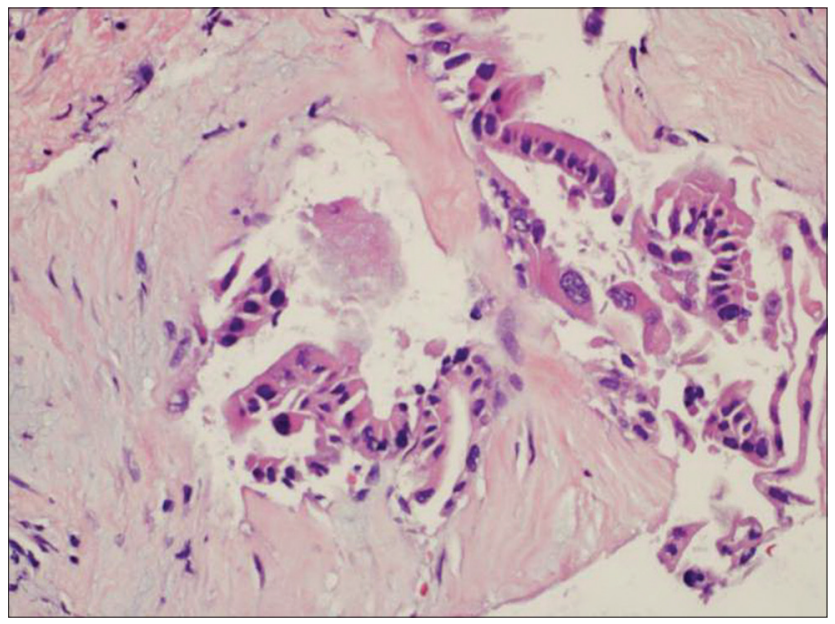

Figure 3: Biopsy showing mucinous epithelium with highly atypical nuclei and nuclear pleomorphism (H and $\mathrm{E})$

As a retrospective study, this investigation does have limitations. First, we are not able to capture every patient with a pancreatic cyst, and as such, we cannot make a determination as to the overall accuracy of the AGA guidelines. Rather, we can only capture the patients who were referred for EUS. Second, given the small number of patients with early neoplasia, we cannot determine the actual reasons these patients were referred for EUS or surgery. Finally, we do not have longitudinal follow-up for patients with negative EUS, or those patients who underwent an evaluation at another institution.

\section{Conclusion}

Our data indicate that EUS is a useful tool in the management of patients with incidental pancreatic cysts, and would identify patients with early cancer that would be missed by radiographic follow-up alone, as advocated by the current AGA guidelines. These findings would warrant a larger prospective study to assess the utility of EUS in identifying early neoplasia, along with the cost efficacy of this strategy compared to radiographic surveillance alone.

\section{Financial support and sponsorship} Nil.

\section{Conflicts of interest}

There are no conflicts of interest. 


\section{REFERENCES}

1. Laffan TA, Horton KM, Klein AP, Berlanstein B, Siegelman SS, Kawamoto S, et al. Prevalence of unsuspected pancreatic cysts on MDCT. AJR Am J Roentgenol 2008;191:802-7.

2. Girometti R, Intini $\mathrm{S}$, Brondani $\mathrm{G}$, Como $\mathrm{G}$, Londero $\mathrm{F}$, Bresadola $\mathrm{F}$, et al. Incidental pancreatic cysts on 3D turbo spin echo magnetic resonance cholangiopancreatography: Prevalence and relation with clinical and imaging features. Abdom Imaging 2011;36:196-205

3. Lee KS, Sekhar A, Rofsky NM, Pedrosa I. Prevalence of incidental pancreatic cysts in the adult population on MR imaging. Am J Gastroenterol 2010;105:2079-84.

4. Matsubara S, Tada M, Akahane M, Yagioka H, Kogure H, Sasaki $\mathrm{T}$, et al. Incidental pancreatic cysts found by magnetic resonance imaging and their relationship with pancreatic cancer. Pancreas 2012;41:1241-6.

5. Zhang XM, Mitchell DG, Dohke M, Holland GA, Parker L. Pancreatic cysts: Depiction on single-shot fast spin-echo MR images. Radiology 2002;223:547-53.

6. Pyke CM, van Heerden JA, Colby TV, Sarr MG, Weaver AL. The spectrum of serous cystadenoma of the pancreas. Clinical, pathologic, and surgical aspects. Ann Surg 1992;215:132-9.

7. Sarr MG, Carpenter HA, Prabhakar LP, Orchard TF, Hughes S, van Heerden JA, et al. Clinical and pathologic correlation of 84 mucinous cystic neoplasms of the pancreas: Can one reliably differentiate benign from malignant (or premalignant) neoplasms? Ann Surg 2000;231:205-12.

8. Klöppel G. Clinicopathologic view of intraductal papillary-mucinous tumor of the pancreas. Hepatogastroenterology 1998;45:1981-5.

9. Warshaw AL, Compton $\mathrm{CC}$, Lewandrowski $\mathrm{K}$, Cardenosa G,
Mueller PR. Cystic tumors of the pancreas. New clinical, radiologic, and pathologic observations in 67 patients. Ann Surg 1990;212:432-43.

10. Tanaka M, Chari S, Adsay V, Fernandez-del Castillo C, Falconi M, Shimizu M, et al. International consensus guidelines for management of intraductal papillary mucinous neoplasms and mucinous cystic neoplasms of the pancreas. Pancreatology 2006;6:17-32.

11. Kaimakliotis P, Riff B, Pourmand K, Chandrasekhara V, Furth EE, Siegelman ES, et al. Sendai and fukuoka consensus guidelines identify advanced neoplasia in patients with suspected mucinous cystic neoplasms of the pancreas. Clin Gastroenterol Hepatol 2015;13:1808-15.

12. Tanaka M, Fernández-del Castillo C, Adsay V, Chari S, Falconi M, Jang JY, et al. International consensus guidelines 2012 for the management of IPMN and MCN of the pancreas. Pancreatology 2012;12:183-97.

13. Vege SS, Ziring B, Jain R, Moayyedi P, Clinical Guidelines Committee, American Gastroenterology Association. et al. American gastroenterological association institute guideline on the diagnosis and management of asymptomatic neoplastic pancreatic cysts. Gastroenterology 2015;148:819-22.

14. Lekkerkerker SJ, Besselink MG, Busch OR, Verheij J, Engelbrecht MR, Rauws EA, et al. Comparing 3 guidelines on the management of surgically removed pancreatic cysts with regard to pathological outcome. Gastrointest Endosc 2017;85:1025-31.

15. Ma GK, Goldberg DS, Thiruvengadam N, Chandrasekhara V, Kochman ML, Ginsberg GG, et al. Comparing American Gastroenterological Association pancreatic cyst management guidelines with Fukuoka consensus guidelines as predictors of advanced neoplasia in patients with suspected pancreatic cystic neoplasms. J Am Coll Surg 2016;223:729-370. 